\title{
Two-step large-volume magnetic separation combined with PCR assay for sensitive detection of Listeria monocytogenes in pasteurized milk
}

\author{
Dan Luo, ${ }^{*} \dagger$ Xiaolin Huang, ${ }^{*} \dagger$ Yan Mao, ${ }^{*}$ Chaochao Chen, $\ddagger$ Fulai Li, ${ }^{*}$ Hengyi Xu, ${ }^{* 1}$ and Yonghua Xiong ${ }^{*} \dagger^{1}$ \\ *State Key Laboratory of Food Science and Technology, Nanchang University, Nanchang 330047, P. R. China \\ †Jiangxi-OAl Joint Research Institute, Nanchang University, Nanchang 330047, P. R. China \\ ‡Jiangxi Normal University, Nanchang 330022, P. R. China
}

\section{ABSTRACT}

Immunomagnetic separation (IMS) is an effective tool for the preconcentration and purification of foodborne pathogens from complex food samples because of its high capture efficiency (CE). In conventional IMS, antibodies are usually conjugated on the surface of magnetic beads (MB); the random orientation and conformation changes of antibodies on the MB surface can decrease their bioactivity. Moreover, the Brownian motion of immobilized antibodies is weakened, thereby rendering their binding efficiency with bacteria lower than that of free antibodies. Thus, abundant antibodies are commonly required to ensure high CE for IMS, particularly for large volumes. In this study, a 2-step largevolume magnetic separation $(10 \mathrm{~mL})$ was proposed to preconcentrate Listeria monocytogenes from pasteurized milk. First, the biotinylated anti- $L$. monocytogenes monoclonal antibodies $(\mathrm{mAb})$ were bound with $L$. monocytogenes in $10 \mathrm{~mL}$ of diluted milk through an antigen-antibody interaction, and then streptavidinlabeled MB were used to capture biotin-mAb coated with L. monocytogenes by biotin and streptavidin interaction. Under optimal conditions, the CE of 2-step magnetic separation was $>90 \%$ with $L$. monocytogenes concentrations ranging from $8 \times 10^{0}$ to $8 \times 10^{4} \mathrm{cfu} / \mathrm{mL}$, whereas the amount of biotin-mAb was 14 fold lower than that of the conventional IMS method. Coupled with a PCR assay, the detection limit of the proposed method was $8 \times 10^{0} \mathrm{cfu} / \mathrm{mL}$ in pure culture and $8 \times$ $10^{1} \mathrm{cfu} / \mathrm{mL}$ in pasteurized milk without any pre-enrichment process. Moreover, the overall detection time, including sample preparation, large-volume magnetic separation, and PCR, took less than $7 \mathrm{~h}$. In summary, the developed 2-step large-volume IMS combined with PCR was highly sensitive and low cost and, thus, has

\footnotetext{
Received May 10, 2017.

Accepted June 17, 2017

${ }^{1}$ Corresponding authors: yhxiongchen@163.com and HengyiXu@ ncu.edu.cn
}

considerable potential for the rapid screening of foodborne pathogenic bacteria.

Key words: two-step large-volume magnetic separation, Listeria monocytogenes, polymerase chain reaction, pasteurized milk

\section{INTRODUCTION}

Listeria monocytogenes is a common food-borne pathogen that ubiquitously exists in environments, including plant, soil, water, and human or animal feces. It can grow at refrigeration temperatures, and even in some fairly extreme conditions (Jooste et al., 2016). Newborns, pregnant women, senior citizens, and immunodeficient people are susceptible to L. monocytogenes (Camargo et al., 2016). Listeriosis caused by L. monocytogenes, mainly through the consumption of contaminated food, can lead to serious infection in humans, with a global mortality rate of $25 \%$ (Mead et al., 1999; Allerberger and Wagner, 2010; de Noordhout et al., 2014). Milk and milk products are identified as among the main food vectors for L. monocytogenes transmission (Jordan et al., 2016). Approximately 2 to $5 \%$ of raw milk products may be contaminated with $L$. monocytogenes from cow feces, soil, straw, and mastitis (Bickley et al., 1996; Laximan et al., 2016). Moreover, L. monocytogenes has also been found in pasteurized milk and milk products; for example, Dalton et al. (1997) reported an outbreak of gastroenteritis and fever among persons who drank chocolate milk contaminated with L. monocytogenes at a picnic and Weissfeld et al. (2017) reported 2 ice cream companies that had a listeriosis outbreak at about the same time in 2015 and 2016. Traditional methods for L. monocytogenes detection are time-consuming because they commonly require 12 to $24 \mathrm{~h}$ pre-enrichment for improving the target bacteria concentration, and thereby fail to meet the requirements of rapid detection in less than $8 \mathrm{~h}$ of assay time. Therefore, developing a sensitive and lowcost method for rapid detection of L. monocytogenes contaminated foods is needed. 
Immunomagnetic separation (IMS) is among the most effective technologies to separate and concentrate target pathogens from complex food matrix; IMS can also eliminate the inhibitory substances in PCR reaction or immunoassay, thereby improving the limit of detection and shortening the assay time (Yang et al., 2013). However, traditional IMS always suffers from its small enrichment factor because it generally applies 1.0 $\mathrm{mL}$ of aqueous solution from $250 \mathrm{~mL}$ of enrichment culture for separation (Chen et al., 2014). In our previous study, we established a large-volume IMS $(10 \mathrm{~mL})$ for L. monocytogenes and Listeria ivanovii separation and concentration. Owing to a higher enrichment factor, the limit of detection of large-volume IMS combined with PCR reached as low as $10 \mathrm{cfu} / \mathrm{g}$ in lettuce samples in less than $7 \mathrm{~h}$ of assay time; however, the antibody consumption in a $10-\mathrm{mL}$ volume IMS reaches up to 70 $\mu \mathrm{g} /$ reaction (Mao et al., 2016). In the conventional IMS method, antibodies are usually immobilized on the surface of magnetic beads (MB) to form immunomagnetic beads through covalent coupling or biotin and a streptavidin (SA) system (Cao et al., 2012). Compared with free antibodies, the Brownian movement of antibodies immobilized on MB is very weak, thereby resulting in poor immunoreaction efficiency between immobilized antibodies and epitopes on the surface of bacteria, particularly in a large separation volume. To ensure high capture efficiency (CE) of immunomagnetic beads to target bacteria, a large amount of antibodies and MB are required in a large-volume IMS. Thus, practical application of large-volume IMS is limited because of its high cost.

In the present study, a novel IMS based on 2-step recognition reaction (2-step IMS) was proposed for the first time to decrease antibody consumption in a largevolume IMS, in which biotin-labeled anti- $L$. monocytogenes monoclonal antibodies $(\mathbf{m A b})$ were first premixed with $L$. monocytogenes in a $10 \mathrm{~mL}$ volume and then the SA-coated MB (SA-MB) and used to capture mAb-coated $L$. monocytogenes by the biotin and SA interaction. The CE of 2-step IMS is influenced by various parameters, including the labeled ratio of biotin and $\mathrm{mAb}$, biotin-mAb, and SA-MB contents, immunoreaction time between biotin-mAb and L. monocytogenes, capture time of SA-MB- and biotin-mAb-coated bacteria, and magnetic separation time, which were systematically investigated and optimized. Owing to the high immunoreaction efficiency of free biotin-mAb and bacteria, the antibody consumption of 2-step IMS in 10 $\mathrm{mL}$ of separation volume reduced by approximately 14 fold compared with that of conventional IMS method. Combined with PCR, the developed 2-step IMS was successfully applied in L. monocytogenes detection with a limit of detection at $8 \times 10^{0} \mathrm{cfu} / \mathrm{mL}$ in pure culture and $8 \times 10^{1} \mathrm{cfu} / \mathrm{mL}$ in pasteurized milk with a total assay time of less than $7 \mathrm{~h}$.

\section{MATERIALS AND METHODS}

\section{Materials and Reagents}

Carboxylated MB with a $180 \mathrm{~nm}$ diameter $(10 \mathrm{mg} /$ $\mathrm{mL}$ ) were obtained from Allrunnano Technology Co. Ltd. (Shanghai, China). Anti-L. monocytogenes mAb were provided by Wuxi Zodoboer Biotech. Co. Ltd. (Wuxi, China). Streptavidin and $N$-hydroxysuccinimide sodium salt (NHSS) activated long-chain biotins were purchased from Hualan Technology Co. Ltd. (Shanghai, China). Bovine serum albumin, 1-ethyl-3-(3-dimethylaminopropyl) carbodiimide (EDC. $\mathbf{H C l})$, NHSS, Tris, glycogen, Triton-X100, ammonium acetate, and $\mathrm{Na}_{2}$ EDTA were from Sigma-Aldrich Chemical Co. (St. Louis, MO). BacteriaGen DNA Kit and lysozyme were bought from ComWin Biotech Co. Ltd. (Beijing, China). Both SA and horseradish peroxidase conjugate were from Beijing ZhongShan-Golden Bridge Biological Technology Co. Ltd. (Beijing, China). PALCAM was obtained from Land Bridge Technology Co. Ltd. (Beijing, China). Pasteurized milk was purchased from the local supermarket.

\section{Bacteria and Culture Conditions}

The strains used in this study as shown in Table 1 . Listeria monocytogenes (ATCC13932) was obtained from the American Type Culture Collection (ATCC) and grown in Luria-Bertani broth on a shaking incubator at $180 \mathrm{rpm}$ overnight at $37^{\circ} \mathrm{C}$. The bacteria solutions were continuously diluted with sterile PBS to different concentrations for IMS experiments. After magnetic separation, $100 \mu \mathrm{L}$ of diluents, including supernatants and mAb-MB bacteria pellets, were spread onto selective PALCAM plates and incubated at $37^{\circ} \mathrm{C}$ for 18 to $24 \mathrm{~h}$. The cell number of L. monocytogenes was determined by counting the colonies grown on the plates.

\section{Preparation of SA-MB and Biotin-mAb}

The SA-MB were prepared according to our previously described method with some modifications (Mao et al., 2016). Briefly, $5.75 \mathrm{mg}$ of EDC. $\mathrm{HCl}$ and $6.52 \mathrm{mg}$ of NHSS were added to $20 \mathrm{mg}$ of carboxylated MB in $10 \mathrm{~mL}$ of sterilized PBS (0.01 $M, \mathrm{pH} 7.4)$ on an HS-3 Vertical Mixer (NingBoScientz Biotechnology Co. Ltd., Zhejiang, China) at room temperature for $1 \mathrm{~h}$. After washing thrice with PBS, $1.6 \mathrm{mg}$ of SA was added into the activated MB. The mixture was reacted at room 


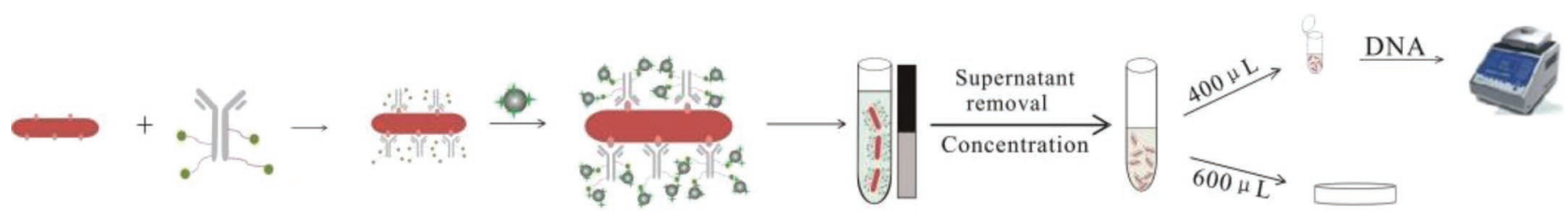

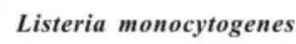

SA-MB

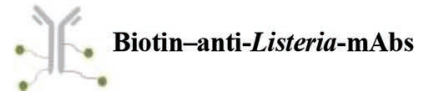

Magnet

Figure 1. Schematic illustration of 2-step magnetic separation combined with PCR for detection of Listeria monocytogenes in a 10-mL volume. SA-MB = streptavidin-coated magnetic beads. Color version available online.

temperature for $2 \mathrm{~h}$ and then blocked with $1 \%$ (wt/ vol) BSA solution for 45 min. The as-prepared SA-MB were purified using an external magnetic field and resuspended with $10 \mathrm{~mL}$ of $0.01 M$ PBS (pH 7.4).

The biotin-mAb were prepared by mixing NHSS activated long-chain biotin and anti-L. monocytogenes $\mathrm{mAb}$ in $0.01 M$ PBS (pH 7.4) with molar ratios of 20:1, 10:1, 5:1, and 1:1. After reaction at room temperature for $4 \mathrm{~h}$, the mixture was transferred into a dialysis bag at $4^{\circ} \mathrm{C}$ for $3 \mathrm{~d}$ to remove free long-chain biotin. Finally, glycerin was added to the as-prepared biotin-mAb solution to a final concentration of $50 \%$ and then stored at $-20^{\circ} \mathrm{C}$ for further use.

\section{2-Step IMS Procedure}

As shown in Figure 1, $5 \mu \mathrm{g}$ of biotin-mAb (the molar ratio of long-chain biotin and $\mathrm{mAb}$ is $20: 1$, named biotin-mA $\left.\mathrm{b}_{20: 1}\right)$ was first added into $10 \mathrm{~mL}$ of PBS buffer $(0.01 M, \mathrm{pH}$ 7.4) containing a certain concentration of L. monocytogenes with gentle shaking at $37^{\circ} \mathrm{C}$ for 1 h. Then, $700 \mu \mathrm{g}$ of SA-MB was added into the above mixture to form an MB-SA-biotin-mAb-bacteria complex. After reaction at $37^{\circ} \mathrm{C}$ for $30 \mathrm{~min}$, the mixture was separated for 3 min using a 0.4-T external magnetic field caused by 2 fabricated magnets $(12.0 \times 2.0 \times$ $1.0 \mathrm{~cm}$; Mao et al., 2016). The MB-SA-biotin-mAbbacteria pellets were resuspended with $1 \mathrm{~mL}$ of sterilized PBS. Among them, 400- $\mu \mathrm{L}$ solutions were used to extract DNA for PCR amplification and the rest were plated on PALCAM to count the bacteria number after appropriate dilution. The $\mathrm{CE}$ was calculated using the equation

$$
\mathrm{CE}(\%)=\left[\mathrm{N}_{\mathrm{b}} /\left(\mathrm{N}_{\mathrm{u}}+\mathrm{N}_{\mathrm{b}}\right)\right] \times 100 \text { (Mao et al., 2016), }
$$

where $\mathrm{N}_{\mathrm{u}}$ is the number of unbound bacteria in the supernatant $(\mathrm{cfu} / \mathrm{mL})$ and $\mathrm{N}_{\mathrm{b}}$ is the number of cells bound to the SA-MB (cfu/mL). All experiments were performed in triplicate. The means of groups were compared via 1-way ANOVA, standard deviation was calculated from the resultant means of the triplicate experiments, and the statistical significance threshold was determined as $P<0.05$ (Shan et al., 2014).

\section{PCR Assay}

Table 2 shows the primer pairs used in this study. Listeria monocytogenes primer for actA amplification was designed using Oligo 6.0 software (http://www .oligo.net/), and the sequence specificity was verified by using Primer BLAST in the NCBI webpage (https:// www.ncbi.nlm.nlm.nih.gov/pmc/). One pair of primer for internal amplification control (IAC), obtained from

Table 1. Bacteria strains used in this study

\begin{tabular}{lll}
\hline Number & Bacteria strains & Source $^{1}$ \\
\hline 1 & Micrococcus luteus & CMCC28003 \\
2 & Shigella flexneri & 2a 2457T \\
3 & Cronobacter sakazakii & ATCC29544 \\
4 & Staphylococcus aureus & CMCC26003 \\
5 & Bacillus cereus & JDZ0043Y \\
6 & Salmonella Enteritidis & CMCC50041 \\
7 & Salmonella Typhimurium & ATCC13311 \\
8 & Pseudomonas aeruginosa & CICC21562 \\
9 & Escherichia coli O157:H7 & CMCC44102 \\
10 & Escherichia coli & ATCC25922 \\
11 & Listeria welshimeri & ATCC35897 \\
12 & Listeria seeligeri & ATCC35967 \\
13 & Listeria monocytogenes & ATCC13932 \\
14 & Listeria monocytogenes & CMCC54007 \\
15 & Listeria ivanovii & ATCC19119 \\
16 & Listeria innocua & NCTC11288 \\
17 & Listeria grayi & ATCC25401 \\
\hline
\end{tabular}

${ }^{1}$ ATCC $=$ American Type Culture Collection; $\mathrm{CMCC}=$ China Medical Culture Collection; CICC = China Center of Industrial Culture Collection; NCTC $=$ National Collection of Type Cultures; JDZ0043Y was obtained from JX-CDC (Jiang Xi Province Center for Disease Control and Prevention). 
Table 2. Primers used in the PCR

\begin{tabular}{|c|c|c|c|c|}
\hline Target bacteria & Primer sequence $\left(5^{\prime}-3^{\prime}\right)^{1}$ & $\begin{array}{l}\text { Product } \\
\text { length } \\
\text { (bp) }\end{array}$ & $\begin{array}{c}\text { Primer } \\
\text { concentration } \\
(\mu M)\end{array}$ & Reference \\
\hline Listeria monocytogenes & $\begin{array}{l}\text { act } A-\mathrm{F}-5^{\prime} \text {-GCGACAGATAGCGAAGATTCCAG-3' } \\
\text { act } A \text {-R-5'-GCCACATTATCGCTTTGTTCACTG-3' }\end{array}$ & 257 & 1.0 & This study \\
\hline $16 \mathrm{~S}$ rRNA & $\begin{array}{l}\text { 16S rRNA-F-5'-CCTACGGGAGGCAGCAGT-3' } \\
\text { 16S rRNA-R-5'-CGTTTACGGCGTGGACTAC-3' }\end{array}$ & 475 & 0.1 & (Chiang et al., 2006) \\
\hline
\end{tabular}

${ }^{1} \mathrm{~F}=$ forward; $\mathrm{R}=$ reverse

a previous report (Chiang et al., 2006), was used to indicate false-negative results. The total reaction volume for PCR amplification was $20 \mu \mathrm{L}$, including $8 \mu \mathrm{L}$ of $2.5 \times$ reaction mix, $5 \mathrm{U}$ of hot start Taq DNA polymerase (AGCU ScienTech Inc., Wuxi, China), $2 \mu \mathrm{L}$ of each DNA template containing L. monocytogenes and Escherichia.coli (for IAC), $1.0 \mu \mathrm{L}$ of actA primer, 0.1 $\mu \mathrm{L}$ of $16 \mathrm{~S}$ rRNA primer, and sterile water. The PCR amplification conditions were $95^{\circ} \mathrm{C}$ for 5 min, followed by 35 cycles of $94^{\circ} \mathrm{C}$ for $30 \mathrm{~s}, 62^{\circ} \mathrm{C}$ for $30 \mathrm{~s}$ and $72^{\circ} \mathrm{C}$ for $30 \mathrm{~s}$, and a final stretch at $72^{\circ} \mathrm{C}$ for $10 \mathrm{~min}$. Afterward, the PCR products were run with $2.5 \%$ agarose gel electrophoresis stained with ethidium bromide, and imaged under a UV transilluminator (Bio Rad, Hercules, CA).

\section{Detection of L. monocytogenes in Spiked Milk Samples}

Pasteurized milk was spiked with $L$. monocytogenes at different concentrations and assayed by the proposed method. In brief, $10 \mathrm{~mL}$ of milk was added into $90 \mathrm{~mL}$ of $0.01 \mathrm{M}$ sterilized PBS to form a $10 \%$ homogenate. The L. monocytogenes solutions were spiked to the above homogenates with $L$. monocytogenes final concentrations ranging from $8 \times 10^{0}$ to $8 \times 10^{3} \mathrm{cfu} / \mathrm{mL}$. A total of $5 \mu \mathrm{g}$ of biotin-mAb $\mathrm{b}_{20: 1}$ was added into the L. monocytogenes spiked milk samples. After incubation at $37^{\circ} \mathrm{C}$ for $1 \mathrm{~h}$ with gentle shaking, $700 \mu \mathrm{g}$ of SA-MB was added and the solution was incubated for another $30 \mathrm{~min}$ at $37^{\circ} \mathrm{C}$. Finally, the MB-SA-biotinmAb-bacteria complex was separated magnetically for $3 \mathrm{~min}$ and resuspended in $1 \mathrm{~mL}$ of $0.01 M$ PBS. Among the complex, $400 \mu \mathrm{L}$ of resuspension liquid was used to extract the target DNA for PCR amplification. The DNA extraction was performed with (Mao et al., 2016) $400 \mu \mathrm{L}$ of resuspension liquid heated at $90^{\circ} \mathrm{C}$ for $10 \mathrm{~min}$ in a thermostatically controlled water bath to separate the L. monocytogenes from MB-mAb-bacteria and a magnet was used to separate the MB. The supernatant was removed by centrifugation $(13,400 \times$ $g$, room temperature, $3 \mathrm{~min}$ ), and the precipitate was then resuspended in the enzymatic lysis buffer $(180 \mu \mathrm{L})$ containing $\mathrm{Na}_{2}$ EDTA $(2 \mathrm{~m} M)$, Tris $(20 \mathrm{~m} M)$, Triton-
$\mathrm{X} 100(1.2 \%)$, and lysozyme $(20 \mathrm{mg} / \mathrm{mL})$ at $37^{\circ} \mathrm{C}$ for 30 min. Proteinase K $(20 \mu \mathrm{L})$ and Buffer GL $(200 \mu \mathrm{L}$; ComWin Biotech Co. Ltd.) were added and vortexed for blending adequately. After incubation for $30 \mathrm{~min}$ at $56^{\circ} \mathrm{C}$, the mixtures were treated with equal volumes of phenol/chloroform/isoamyl alcohol (25:24:1), and then centrifuged at $13,400 \times g$ at room temperature for $3 \mathrm{~min}$. A total of $66.5 \mu \mathrm{L}$ of ammonium acetate $(7.5 \mathrm{~mol} / \mathrm{L}), 1.5 \mu \mathrm{L}$ of glycogen $(20 \mathrm{mg} / \mathrm{mL})$, and 388.5 $\mu \mathrm{L}$ of ethanol were added into approximately $400 \mu \mathrm{L}$ of supernatant. After standing for $30 \mathrm{~min}$ at $0^{\circ} \mathrm{C}$, the mixture was centrifuged at $13,400 \times g$ for $30 \min \left(4^{\circ} \mathrm{C}\right)$ to discard the supernatant. The precipitate was washed twice with $150 \mu \mathrm{L}$ of ethanol (70\%) and dissolved in 10 $\mu \mathrm{L}$ of Buffer GE for PCR.

\section{RESULTS AND DISCUSSION}

\section{Characterization of Biotin-mAb}

As shown in Figure 1, the MB bound on the surface of L. monocytogenes were based on biotin and SA interaction because the SA is a tetrameric protein that can combined with 4 biotin moleculars (Shan et al., 2014). The labeled amounts of biotin to mAb can influence the amounts and binding efficiency of SA-MB on the surface of the bacteria, and further effect the CE of SA-MB to L. monocytogenes. In the present study, we synthesized 4 kinds of biotin-mAb with the labeled biotin-to-mAb ratio at 1:1, 5:1, 10:1, and 20:1. To characterize the amounts of biotin coupled on $\mathrm{mAb}$, various biotin-mAb with concentrations ranging from 0.156 to $5 \mu \mathrm{g} / \mathrm{mL}$ were coated on the ELISA plates and then reacted with SA-horseradish peroxidase conjugate. $\mathrm{OD}_{450}$ (optical density at $450 \mathrm{~nm}$ ) value was used to evaluate the combining capacity of biotin-mAb to SA. As shown in Figure 2, $\mathrm{OD}_{450}$ values increased with the increased biotin-to-mAb ratio; when the labeled ratio of biotin to $\mathrm{mAb}$ was $20: 1$, the $\mathrm{OD}_{450}$ values was still up to 2.0 even if the concentration of $\mathrm{mAb}$ was as low as $0.625 \mu \mathrm{g} / \mathrm{mL}$, indicating that sufficient amounts of biotin coupled on the mAb. However, excessive biotin coupled on the $\mathrm{mAb}$ may block the binding site of $\mathrm{mAb}$ to antigen 
Table 3. The influence of biotin-monoclonal antibodies $(\mathrm{mAb})$ on capture efficiency $(\mathrm{CE})$

\begin{tabular}{lcccc}
\hline & \multicolumn{4}{c}{ Molar ratio of biotin to mAb } \\
\cline { 2 - 5 } Item & $20: 1$ & $10: 1$ & $5: 1$ & $1: 1$ \\
\hline $\mathrm{CE}(\%)$ & $92.54 \pm 3.21$ & $91.67 \pm 5.33$ & $76.66 \pm 4.54$ & $47.86 \pm 0.67$ \\
\hline
\end{tabular}

and result in a low $\mathrm{CE}$ of $L$. monocytogenes. Therefore, the effects of biotin-to-mAb ratio on $\mathrm{CE}$ were further evaluated through a 2-step IMS method. Compared with the labeled ratio of biotin-to-mAb at 5:1 ( $\mathrm{CE}=$ $76.66 \pm 4.54 \%)$ and $1: 1(\mathrm{CE}=47.86 \pm 0.67 \%)$, the CE of biotin-mAb with a 20:1 and 10:1 biotin-to-mAb ratio can reach up to $92.54 \pm 3.21$ and $91.67 \pm 5.33 \%$, respectively (shown in Table 3 ). Considering these results, biotin-mAb with 20:1 biotin-to-mAb molar ratio were suggested for subsequent experiments because more biotins on the $\mathrm{mAb}$ is beneficial to improve the binding affinity of SA-MB to mAb.

\section{Optimization of Experimental Parameters of IMS in $10 \mathrm{~mL}$}

In the 2-step IMS system, the contents of biotin-mAb 20:1 and immunoreaction time between $\mathrm{mAb}$ and $L$. monocytogenes, the amounts of SA-MB and capture time of SA-MB to biotin-mAb 20:1-coated bacteria, and the magnetic separation time are considered the most important factors that affected the $\mathrm{CE}$ of $\mathrm{MB}$ to L. monocytogenes. The dosage of biotin-mAb 20:1 was optimized by adding $1,2,3,5,7,9$, and $11 \mu \mathrm{g}$ of biotin$\mathrm{mAb} 20: 1$ to $10 \mathrm{~mL}$ of PBS buffer containing $8 \times 10^{4}$ $\mathrm{cfu} / \mathrm{mL}$ of L. monocytogenes, and $700 \mu \mathrm{g}$ of SA-MB was

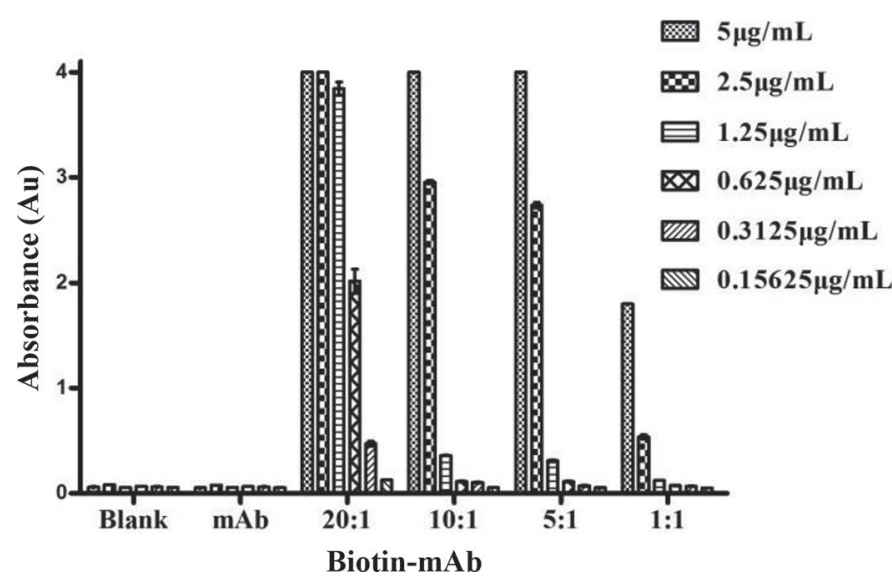

Figure 2. The characterization of biotin-monoclonal antibodies $(\mathrm{mAb})$. The labeled ratio of biotin to $\mathrm{mAb}$ was 20:1, 10:1, 5:1, and 1:1. The absorbance of ELISA were obtained at $405 \mathrm{~nm}$, in which the concentrations of biotin-mAb and $\mathrm{mAb}$ ranged from 5 to $0.156 \mu \mathrm{g} / \mathrm{mL}$. Error bars represent the SD of 3 replicates. used to capture the biotin-mAb 20:1-coated bacteria complex. The results shown in Figure 3A indicated that the CE of SA-MB to L. monocytogenes increased from $46.30 \pm 4.83$ to $80.37 \pm 7.98 \%$ with the amounts of biotin-mAb 20:1 increasing from 1 to $5 \mu \mathrm{g}$. When the amounts of biotin-mAb 20:1 further increase from 5 to $11 \mu \mathrm{g}$, the CE inversely decreased to $28.93 \pm 9.79 \%$, indicating that the excessive free biotin-mAb 20:1 occupied too many binding sites of SA-MB, resulting in a low CE. When the amounts of biotin-mAb 20:1 was between 3 and $5 \mu \mathrm{g}$, CE were not significantly different $(P>0.05, \mathrm{n}=3)$. To ensure sufficient $\mathrm{mAb}$ combined with L. monocytogenes, $5 \mu \mathrm{g}$ of biotin-mAb 20:1 was suggested for subsequent experiments. The immunoreaction time was optimized by incubating the mixture of biotin-mAb 20:1 and L. monocytogenes at $37^{\circ} \mathrm{C}$ for 30 , 45, 60, 90, and $120 \mathrm{~min}$. The results shown in Figure $3 \mathrm{~B}$ indicated that the $\mathrm{CE}$ increased from $45.62 \pm 6.43$ to $91 \pm 8.66 \%$ when immunoreaction time was between 30 and $60 \mathrm{~min}$, and then reached a plateau when the immunoreaction time was further extended to $120 \mathrm{~min}$. Therefore, $60 \mathrm{~min}$ of immunoreaction time was enough to ensure a high $\mathrm{CE}$ of $L$. monocytogenes. The effects of SA-MB contents on the CE were assayed by adding $100,300,500,700$, and $900 \mu \mathrm{g}$ of SA-MB to capture biotin-mAb 20:1-coated bacteria complex. As shown in Figure 3C, CE gradually increased from $61.38 \pm 9.66$ to $91.24 \pm 3.96 \%$ as the amounts of SA-MB increased from 100 to $500 \mu \mathrm{g}$, and then stabilized when SA-MB contents further increased to $900 \mu \mathrm{g}(P>0.05, \mathrm{n}=$ 3). However, when SA-MB content was $500 \mu \mathrm{g}, \mathrm{CE}$ decreased significantly at low bacteria concentrations of $8 \times 10^{0}$ to $8 \times 10^{1} \mathrm{cfu} / \mathrm{mL}$ because the increased free biotin-mAb in the solution can consume large amounts of SA-MB, whereas $700 \mu \mathrm{g}$ of SA-MB was sufficient to ensure a high CE (more than 90\%) for the L. monocytogenes concentration from $8 \times 10^{0}$ to $8 \times 10^{4} \mathrm{cfu} /$ $\mathrm{mL}$ (Figure 3D). The results of effects of capture time between SA-MB and biotin-mAb 20:1-coated bacteria complex on the CE are shown in Figure 3E; CE gradually increased and reached a high constant value of $84.94 \pm 2.75 \%$ with the capture time increasing from 10 to 30 min. Finally, the separation time of SA-MB on the magnetic field was also optimized. The results in Figure $3 \mathrm{~F}$ show that $\mathrm{CE}$ increased from $82.40 \pm 3.56$ to $91.76 \% \pm 3.39 \%$ as the separation time increased from 

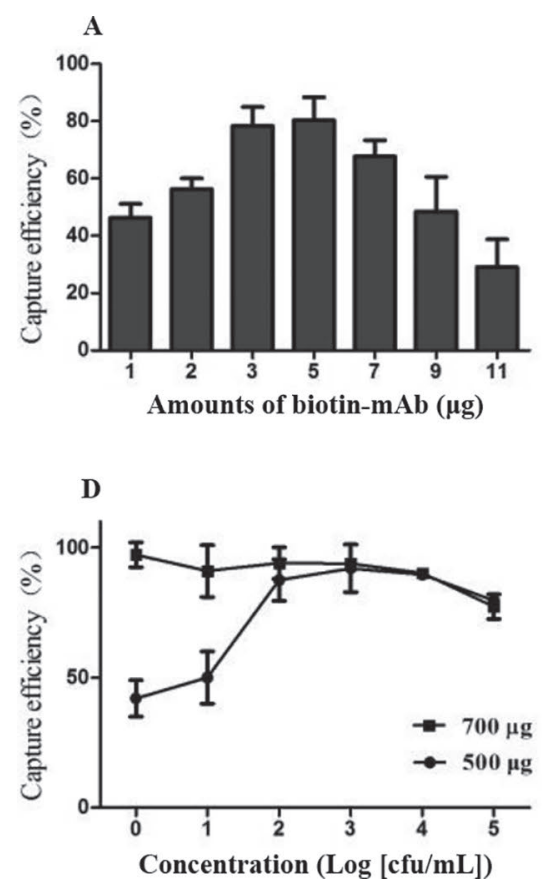
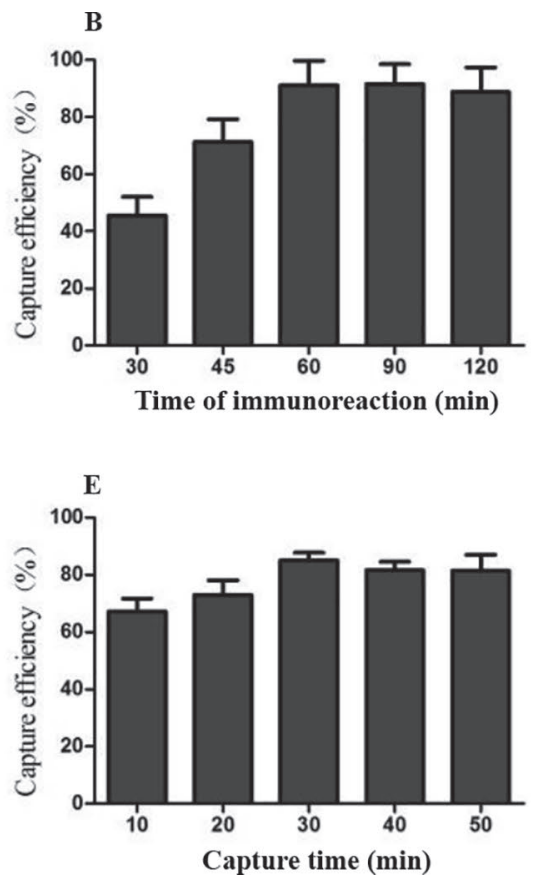
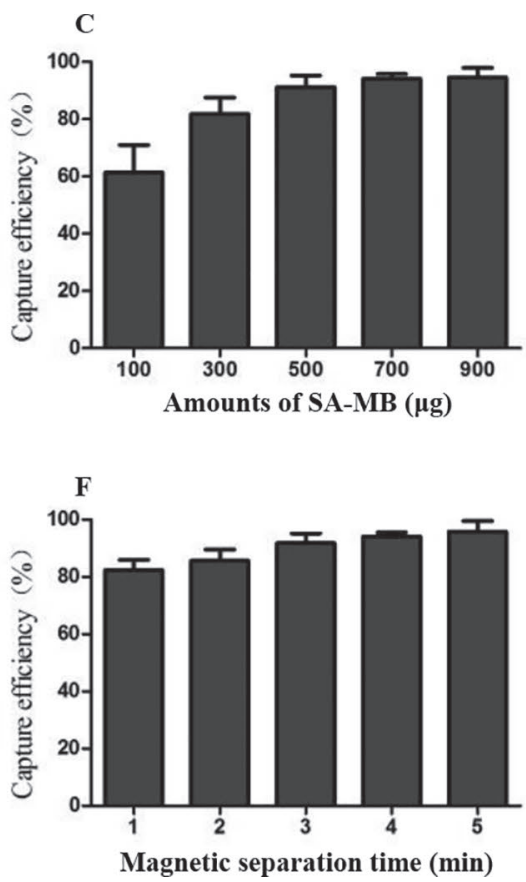

Figure 3. Optimization of experimental parameters via (A) the amounts of biotin-monoclonal antibodies (mAb, ratio of 20:1; 60 min immunoreaction time and 5 min magnetic separation time), (B) immunoreaction time, (C) the amounts of streptavidin-labeled magnetic beads (SA-MB), (D) 500 and $700 \mu \mathrm{g}$ of SA-MB used in pure culture $\left(8 \times 10^{0}-8 \times 10^{5} \mathrm{cfu} / \mathrm{mL}\right)$, (E) capture time, and $(\mathrm{F})$ magnetic separation time. Error bars represent the SD of 3 replicates.

1 to 3 min. Thus, the optimized parameters for 2-step IMS were $5 \mu \mathrm{g}$ of biotin-mAb 20:1 added to $10 \mathrm{~mL}$ of sample volume (the bacteria concentration ranges from $8 \times 10^{0}$ to $8 \times 10^{5} \mathrm{cfu} / \mathrm{mL}$ ). After antibody and bacteria interaction at $37^{\circ} \mathrm{C}$ for $60 \mathrm{~min}, 700 \mu \mathrm{g}$ of SA-MB was added and continually reacted with biotin-mAb and bacteria complex for $30 \mathrm{~min}$. Then, the MB-SAbiotin-mAb-bacteria pellets were separated for $3 \mathrm{~min}$ using a 0.4 -T external magnetic field.

The specificity of the 2-step IMS in $10 \mathrm{~mL}$ volume was investigated by testing the $\mathrm{CE}$ for 17 different pathogens, including 7 Listeria strains and 10 nontarget strains (Table 1). As seen in Figure 4, CE was more than $80 \%$ for Listeria strains $\left(10^{4} \mathrm{cfu} / \mathrm{mL}\right)$ except for Listeria grayi and Listeria seeligeri (approximately $60 \%$ ), whereas $\mathrm{CE}$ of nontarget bacteria was less than $4 \%\left(10^{5} \mathrm{cfu} / \mathrm{mL}\right)$. The results showed that the proposed 2-step IMS method has high specificity for detection of Listeria species.

\section{Optimization of PCR Conditions}

In the present study, we designed 2 pairs of primers to ensure specificity of PCR assay, including act $A-\mathrm{F} / \mathrm{R}$ for the specific amplification of a 257-bp fragment from the actA of L. monocytogenes, and $16 \mathrm{~S} \mathrm{rRNA}-\mathrm{F} / \mathrm{R}$ for the amplification of a 475-bp fragment from the $16 \mathrm{~S}$ rRNA
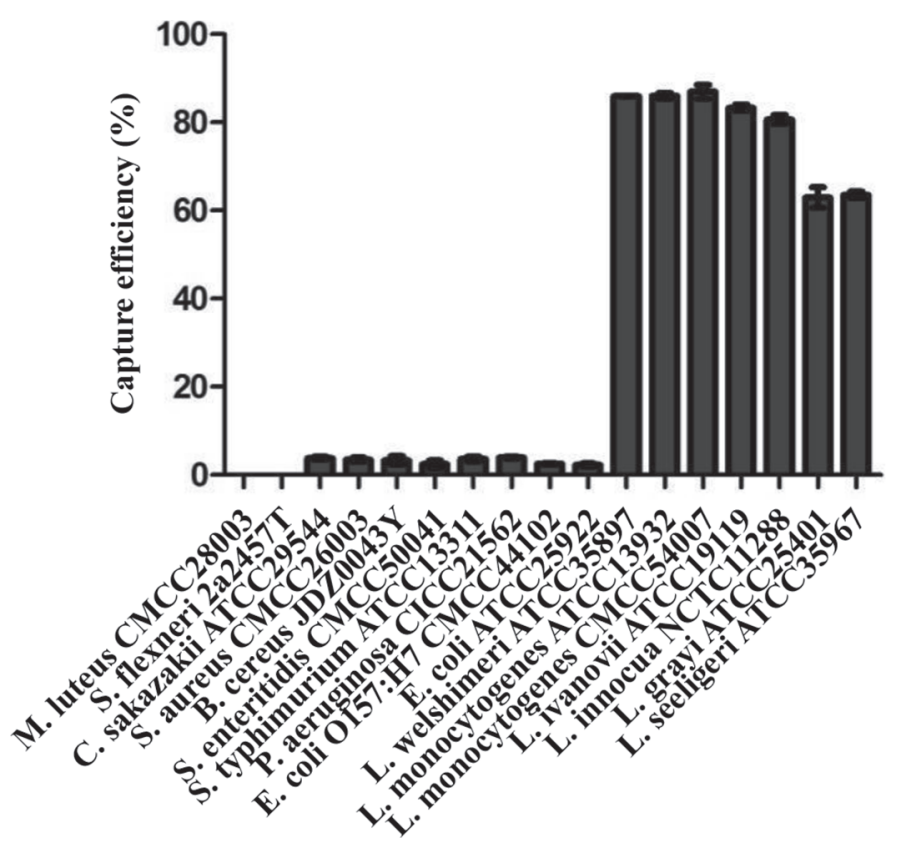

Figure 4. Specificity of 2 -step magnetic separation. The concentrations of Listeria strains were all $10^{4} \mathrm{cfu} / \mathrm{mL}$; other nontarget strains were all $10^{5} \mathrm{cfu} / \mathrm{mL}$. All experiments were performed under the optimal conditions. Error bars represent the SD of 3 replicates. See Table 1 for a full description of strains used. 


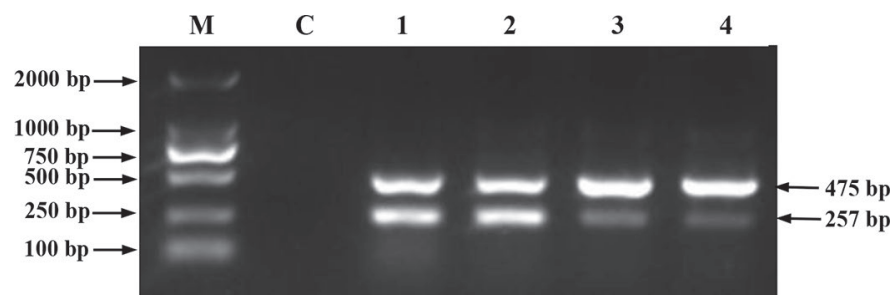

Figure 5. Results of 2-step large-volume magnetic separation combined with PCR for detection of Listeria monocytogenes in pure culture. Lane M = DL 2000 DNA Marker (TaKaRa, Biotech Co. Ltd., Dalian, China); lane $\mathrm{C}=$ negative control; lanes $1-4=8 \times 10^{3}$ to $8 \times$ $10^{0} \mathrm{cfu} / \mathrm{mL}$ of culture, respectively.

gene that acted as an IAC in PCR. The 16S rRNA gene exists in all bacteria genome and has high conservatism and specificity; it can completely consume deoxynucleotide triphosphates substrates with the actA primer during PCR, and thereby decrease the sensitivity for amplification of low concentrations of L. monocytogenes. Therefore, we optimized the concentrations of 2 pairs of primers and the annealing temperature at different concentrations of L. monocytogenes using an orthogonal experimental design (Supplemental Figure S1; https:// doi.org/10.3168/jds.2017-13140). The optimum primer concentrations were $1.0 \mu M$ for actA primer and 0.1 $\mu M$ for $16 \mathrm{~S}$ rRNA. The optimal annealing temperature was set at $62^{\circ} \mathrm{C}$. Under the optimized PCR conditions, 2 specific PCR fragments can be produced even if the concentration of L. monocytogenes was as low as $8 \times$ $10^{0} \mathrm{cfu} / \mathrm{mL}$ in pure culture (Figure 5).

\section{Detection of L. monocytogenes in Milk Using 2-Step IMS and PCR}

To verify the feasibility of 2-step IMS combined with PCR for sensitive detection of $L$. monocytogenes in milk samples, the pasteurized milk samples were diluted with PBS buffer for 10 times, and then the

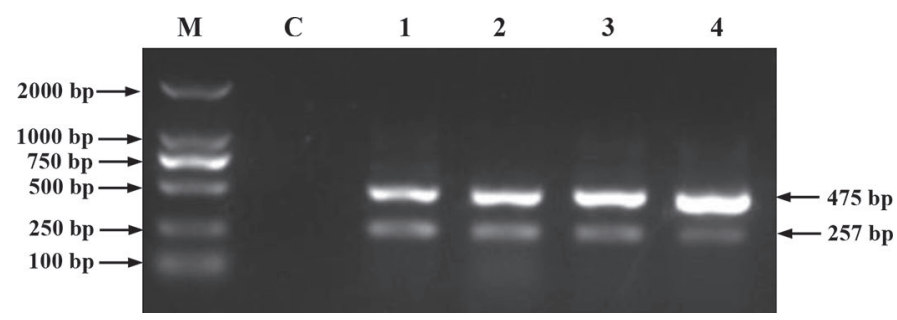

Figure 6. Results of 2-step large-volume magnetic separation combined with PCR for detection Listeria monocytogenes in pasteurized milk. Lane M = DL 2000 DNA Marker (TaKaRa, Biotech Co. Ltd., Dalian, China); lane $\mathrm{C}=$ negative control; lanes $1-4=8 \times 10^{3}$ to $8 \times$ $10^{0} \mathrm{cfu} / \mathrm{mL}$ of culture, respectively. diluent was spiked with $L$. monocytogenes at different concentrations from $8 \times 10^{0}$ to $8 \times 10^{3} \mathrm{cfu} / \mathrm{mL}$. All artificially contaminated milk samples were analyzed by using 2 -step IMS combined with PCR. The results in Figure 6 show that the PCR bands of actA and $16 \mathrm{~S}$ rRNA genes were clearly observed in agarose gel even when the L. monocytogenes concentration was as low as $8 \times 10^{1} \mathrm{cfu} / \mathrm{mL}$, indicating that proposed method possesses an high sensitivity to meet the requirement of L. monocytogenes rapid detection in real milk samples without any enrichment process.

\section{CONCLUSIONS}

We developed a 2-step magnetic separation combined with PCR for sensitive detection of L. monocytogenes in a $10-\mathrm{mL}$ volume without any pre-enrichment. Under optimal conditions, the amount of biotin-mAb 20:1 was reduced by 14 fold compared with a previous study using the same amount of SA-MB. The CE was higher than $90 \%$ when the concentration of L. monocytogenes was less than $8 \times 10^{4} \mathrm{cfu} / \mathrm{mL}$ in pure culture, and the limit of detection reached as low as $8 \times 10^{0} \mathrm{cfu} / \mathrm{mL}$ in pure culture and $8 \times 10^{1} \mathrm{cfu} / \mathrm{mL}$ in pasteurized milk. Moreover, the total assay time took less than $7 \mathrm{~h}$, including sample preparation, 2-step magnetic separation, and PCR. In summary, the proposed method provided a novel strategy to reduce the antibody consumption in a large separation volume based on a 2-step magnetic separation, and this method exhibits considerable potential for rapid and sensitive detection of L. monocytogenes or other common pathogens in complex food samples without further pre-enrichment.

\section{ACKNOWLEDGMENTS}

This work was supported by National Natural Science Foundation of China (Beijing; 31271863), Training Plan for the Main Subject of Academic Leaders of Jiangxi Province (Nanchang, China; 20142BCB22004), and Training Plan for the Young Scientist (Jinggang Star) of Jiangxi Province (Nanchang, China; 20142BCB23004).

\section{REFERENCES}

Allerberger, F., and M. Wagner. 2010. Listeriosis: A resurgent foodborne infection. Clin. Microbiol. Infect. 16:16-23.

Bickley, J., J. Short, D. McDowell, and H. Parkes. 1996. Polymerase chain reaction (PCR) detection of Listeria monocytogenes in diluted milk and reversal of PCR inhibition caused by calcium ions. Lett. Appl. Microbiol. 22:153-158.

Camargo, A. C., J. J. Woodward, and L. A. Nero. 2016. The continuous challenge of characterizing the foodborne pathogen Listeria monocytogenes. Foodborne Pathog. Dis. 13:405-416. 
Cao, M., Z. Li, J. Wang, W. Ge, T. Yue, R. Li, V. L. Colvin, and W. Y. William. 2012. Food related applications of magnetic iron oxide nanoparticles: Enzyme immobilization, protein purification, and food analysis. Trends Food Sci. Technol. 27:47-56.

Chen, J., X. Shi, A. G. Gehring, and G. C. Paoli. 2014. Automated immunomagnetic separation for the detection of Escherichia coli O157: H7 from spinach. Int. J. Food Microbiol. 179:33-37.

Chiang, Y. C., C. Y. Yang, C. Li, Y. C. Ho, C. K. Lin, and H. Y. Tsen. 2006. Identification of Bacillus spp., Escherichia coli, Salmonella spp., Staphylococcus spp. and Vibrio spp. with $16 \mathrm{~S}$ ribosomal DNA-based oligonucleotide array hybridization. Int. J. Food Microbiol. 107:131-137.

Dalton, C. B., C. C. Austin, J. Sobel, P. S. Hayes, W. F. Bibb, L. M. Graves, B. Swaminathan, M. E. Proctor, and P. M. Griffin. 1997. An outbreak of gastroenteritis and fever due to Listeria monocytogenes in milk. N. Engl. J. Med. 336:100-105.

de Noordhout, C. M., B. Devleesschauwer, F. J. Angulo, G. Verbeke, J. Haagsma, M. Kirk, A. Havelaar, and N. Speybroeck. 2014. The global burden of listeriosis: A systematic review and meta-analysis. Lancet Infect. Dis. 14:1073-1082.

Jooste, P., A. Alvarez-Ordoñez, K. Jordan, and D. Leong. 2016. Listeria monocytogenes in food: Control by monitoring the food processing environment. Afr. J. Microbiol. Res. 10:1-14.

Jordan, K., K. Hunt, and M. Dalmasso. 2016. Listeria monocytogenes in milk products. Pages 289-315 in Microbes in Food and Health. Springer, New York, NY.
Laximan, S., S. Kaur, R. Aulakh, and J. Gill. 2016. Molecular characterization of Listeria monocytogenes in bovine milk and evaluating the sensitivity of PCR for direct detection in milk. Indian J. Anim. Sci. 86:512-517.

Mao, Y., X. Huang, S. Xiong, H. Xu, Z. P. Aguilar, and Y. Xiong. 2016. Large-volume immunomagnetic separation combined with multiplex PCR assay for simultaneous detection of Listeria monocytogenes and Listeria ivanovii in lettuce. Food Contr. 59:601-608.

Mead, P. S., L. Slutsker, V. Dietz, L. F. McCaig, J. S. Bresee, C. Shapiro, P. M. Griffin, and R. V. Tauxe. 1999. Food-related illness and death in the United States. Emerg. Infect. Dis. 5:607-625.

Shan, S., Z. Zhong, W. Lai, Y. Xiong, X. Cui, and D. Liu. 2014. Immunomagnetic nanobeads based on a streptavidin-biotin system for the highly efficient and specific separation of Listeria monocytogenes. Food Contr. 45:138-142.

Weissfeld, A. S., N. Landes, H. Livesay, and E. Trevino. 2017. Listeria monocytogenes contamination of ice cream: A rare event that occurred twice in the last two years. Clin. Microbiol. Newsl. 39:19-22.

Yang, Y., F. Xu, H. Xu, Z. P. Aguilar, R. Niu, Y. Yuan, J. Sun, X. You, W. Lai, and Y. Xiong. 2013. Magnetic nano-beads based separation combined with propidium monoazide treatment and multiplex PCR assay for simultaneous detection of viable Salmonella Typhimurium, Escherichia coli O157: $\mathrm{H7}$ and Listeria monocytogenes in food products. Food Microbiol. 34:418-424. 